\title{
DESIGN OF DETECTION DEVICE FOR CU CONTAMINATED WATER USING RED DIODE LASER AND PHOTODIODA SENSOR
}

\author{
Frida Agung Rakhmadi*, Siti Rofikhoh \\ Department of Physics, Science and Technology of Faculty, Sunan Kalijaga Yogyakarta \\ Jl. Marsda Adisucipto No.1 Yogyakarta 55281
}

\begin{abstract}
The research on making detection system of $\mathrm{Cu}$ contaminated water based on red diode laser and photodiode sensor has been done. The purpose of this research was to know the characteristic of photodiode sensor, to make and to test the detection system of $\mathrm{Cu}$ contaminated water based on red diode laser and photodiode sensor. This research was conducted in five phases: characterization of photodiode sensor, making data acquisition system, processing and analyzing of training sample data, making of the detection system, and implementation of detection system on test samples. The results of research showed that photodiode sensor used in this research has transfer function of $\mathrm{V}=0,0156 * \mathrm{I}+1,1897$ with relation of input-output was very strong $(\mathrm{r}=0,989)$; sensitivity was 0,0156 volts / lux; repeatability was $98,31 \%$; and saturation for the light intensity >200 lux. Meanwhile, the success rate of detection system implementation on $\mathrm{Cu}$ contaminated water was $97,5 \%$.
\end{abstract}

Keywords: Detection; Cu; Red Diode Laser; Photodiode Sensor

\section{Introduction}

Water is one of the important elements in human life. About three-quarters of the human body consist of water. In addition, groundwater around us has also contributed to human life, such as for drinking, cooking, bathing, and others. Therefore, as a part of our gratitude to God S.W.T., then the water in our environment should be kept well.

Along with the advancement of human life, the need for clean water is also increasing. However, we often encounter water in our environment is no longer in clean condition, but already contaminated with pollutants. If the presence of water pollutants are not considered, in the future, we can experience a clean water crisis.

One of the most common water pollutants is heavy metals. Currently, the presence of heavy metals in water is easy to find. This is a negative effect of the development of the metal industry where the industry does not have a metal waste storage/processing unit so that its metal waste is discharged directly into the environment.

Efforts to maintain clean water should always be done throughout the ages. One effort that can be done is the monitoring of clean water from heavy metals. One type of heavy metal is $\mathrm{Cu}$ metal. This research will focus on the detection of water contaminated with copper $(\mathrm{Cu})$ metals.

The most commonly used tool for detecting the presence of $\mathrm{Cu}$ in water is Atomic Absorption Spectroscopy (AAS). This detection tool has advantages in terms of ease of operation, the speed of data readings, and its sensitivity to changes in the concentration of detected samples. ${ }^{1}$ However, not all laboratories have it because of its relatively expensive equipment and the high cost of care. $^{2}$

To cover the weaknesses of AAS, several types of research on the development of $\mathrm{Cu}$ detection methods have been done. In addition to AAS, the presence of $\mathrm{Cu}$ can be detected

\footnotetext{
*Corresponding author.

E-Mail: agungfrida@yahoo.co.id
} 
using electromagnetic induction ${ }^{3}$ and fluorescence. ${ }^{4}$

This study aims to increase the treasure of $\mathrm{Cu}$ contaminated water detection equipment. In this research, a $\mathrm{Cu}$-contaminated water detection device was made by using red diode laser and photodiode sensor. The use of red laser diodes and photodiode sensors is based on low power consumption and ease of procurement.

\section{Methods}

The research on detection device design of $\mathrm{Cu}$ contaminated water using red diode laser and photodiode sensor was conducted in five phases: characterization of photodiode sensor, manufacturing of data acquisition system, data sampling and processing of training samples, manufacturing of detection system, and implementation of detection device on test samples. The five phases are described as follows.

Characterization of photodiode sensor was conducted to determine the transfer function character and correlation factor of photodiode sensor, sensitivity, repeatability, and its saturation. Sensor characterization was done by varying the input intensity of red diode laser and measuring the output voltage of photodiode sensor. The input data intensity of red diode laser and the output voltage of photodiode sensor were further processed in such a way as to obtain transfer function of photodiode sensor and its correlation factor, sensitivity, repeatability, and its saturation.

Manufacturing of data acquisition system was done through two phases: manufacturing hardware and software. The hardware was manufactured based on block diagram as shown in Figure 1.

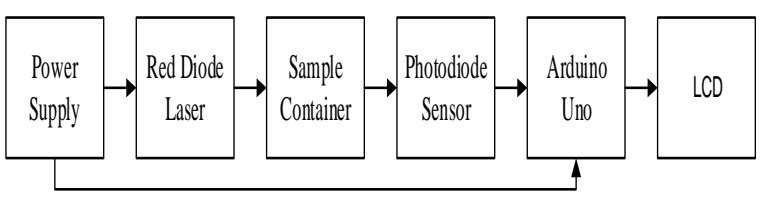

Figure 1. Block diagram of data acquisition system hardware

Data collection from the training sample was aimed to find out the output limit of the data acquisition system for normal water (water with contaminant $\mathrm{Cu} \leqslant 2 \mathrm{ppm}$ ) and abnormal water (water with contaminant $\mathrm{Cu}$ > $2 \mathrm{ppm}) .{ }^{5}$ Each variation of $\mathrm{Cu}$ concentration performed a repetition of data taking 10 times, then calculated the average and its uncertainty. From the results of data processing, it was obtained "boundary value" to be included in the manufacturing of detection system.

Manufacturing of a detection system was done by replacing software of data acquisition system software with the software of detection system. The replacement was done by inserting "boundary value" between the water that can be contaminated $\mathrm{Cu}$ and not allowed that was 4.11 volt.

Implementation of detection system was aimed to test whether detection system that has been made is able to recognize the test sample correctly or not. When the detection device is tested in $\mathrm{Cu}$ contaminated water with a concentration of $\leqslant 2 \mathrm{ppm}$, the system should display "NORMAL" script on the LCD screen. Conversely, if the detection system is tested on $\mathrm{Cu}$ contaminated water with a concentration of $>2 \mathrm{ppm}$, the system should display "ABNORMAL" script on the LCD screen.

\section{Result and Discussion}

\section{Characterization of Photodiode Sensor}

The result of sensor characterization obtained that the photodiode sensor has transfer function $\mathrm{V}=0.0156 * \mathrm{I}+1.1897$ with correlation factor $\mathrm{r}=0.989$, sensitivity was 0,0156 volt / lux, repeatability was $98,31 \%$, and saturation $>200$ lux. Figure 2 illustrated characteristics of the sensor used in this research.

The transfer function showed that greater intensity of the red diode laser light that detected by photodiode sensor, the output voltage of photodiode sensor was also greater with linear similarity. Meanwhile, the correlation factor value of 0.989 gives information that the level of relationship between the variable intensity of light and voltage is very strong. ${ }^{6}$ Transfer function and 
its correlation factor were applicable for the light intensity of 25-200 lux. Researchers could not manufacture light with intensity < 25 lux. The transfer function and its correlation factor also did not apply to light with intensity > 200 lux, because at light intensity > 200 lux sensor has sustained saturation.

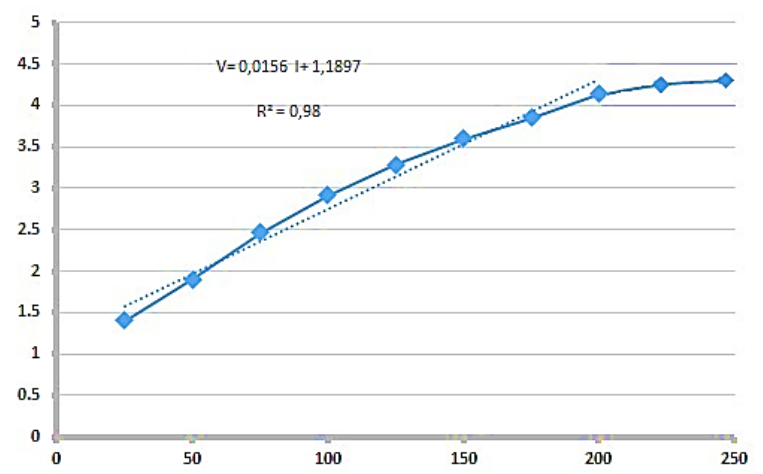

Figure 2. Characteristics of photodiode sensor used in this research.

The sensitivity value of photodiode sensor of 0.0156 volts/lux provided information that increasing of red diode laser light intensity of 1 lux will produce an output voltage of 0.0156 volts. Thus, the photodiode sensor used in this research had small sensitivity because the sensor provided small output to the input. ${ }^{7}$

The repeatability value of photodiode sensor $98.31 \%$ indicated that in repeated measurements the photodiode sensor was able to produce the same value for each measurement, with similarity rate $98.31 \%$. The repeatability value of photodiode sensor had fulfilled the minimum requirement that required by the Indonesian National Standard (SNI) $95.00 \%$ and International Standard (SI) $97.00 \% .^{8}$

\section{Detection System}

The detection system that has been made was shown in Figure 3.

The work step of the detection system in Figure 3 started by connecting the adaptor power to a 9 volt DC voltage source. Further, a sample of $\mathrm{Cu}$ contaminated water was fed into $15 \mathrm{ml}$ bottles, then placed in the sample container. Next, the switch is pressed on, so the LCD and red diode laser will illuminate as an indicator that the tool is ready to be used. The red laser beam on the sample, partially absorbed and part of it will be continued. The laser beam that passed sample will be detected by photodiode sensor, converted to a voltage. The output voltage generated by photodiode sensor will be an input for Arduino Uno R3 microcontroller. The microcontroller will process voltage value of the sensor and compare it with the reference voltage. The results displayed on LCD 16x2.

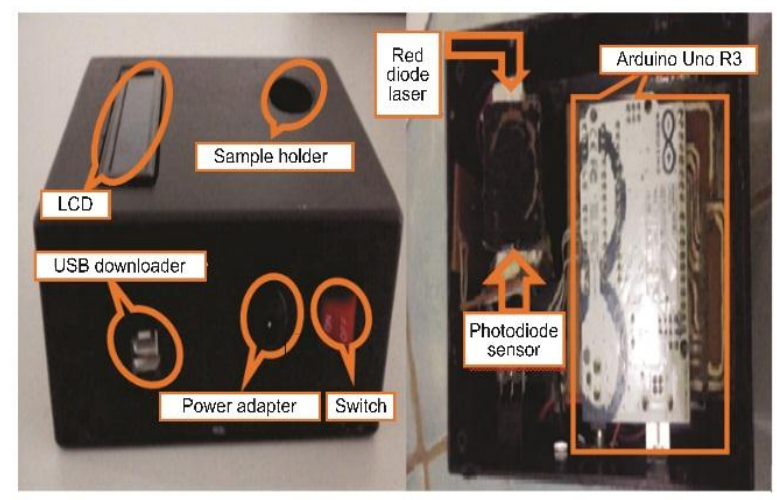

Figure 3. Detection system of $\mathrm{Cu}$ Contaminated Water

\section{Implementation of Detection System}

The implementation result of detection system on the training samples are presented in Table 1.

Table 1. The implementation result of detection system on training samples.

\begin{tabular}{ccc}
\hline No & Cu (ppm) & $\begin{array}{c}\text { Sensor Output } \\
\text { (volt) }\end{array}$ \\
\hline 1 & 1 & $4,246 \pm 0,005$ \\
2 & 2 & $4,115 \pm 0,006$ \\
3 & 3 & $3,964 \pm 0,005$ \\
4 & 4 & $3,824 \pm 0,005$ \\
\hline
\end{tabular}

Table 1 shows that the relationship between the concentration level of $\mathrm{Cu}$ metal in water and the photodiode sensor voltage is inversely proportional. The higher the $\mathrm{Cu}$ metal concentration in water, the lower the output voltage of the photodiode sensor. The magnitude of the output voltage of the photodiode sensor is influenced by the number of electron-hole pairs generated by the amount of light intensity captured by the 
photodiode sensor. ${ }^{6}$ The higher the concentration of $\mathrm{Cu}$ metal in water, then the light absorbed by the water will be more and more, so the light is passed less and less. Because the light is passed less and less, the electron-hole pair is formed also less, so the output voltage of the photodiode sensor is getting smaller.

The results of detection system implementation on test sample have a success of $97.50 \%$. The successful of detection system has met the minimum standard required by SNI and SI. Thus, the contaminated water detection system of $\mathrm{Cu}$ metal that has been made using a red laser and photodiode sensor is able to recognize the test water samples contaminated with $\mathrm{Cu}$ metal well. Thus, this detection system can be an alternative in monitoring water contaminated with $\mathrm{Cu}$ metals. The advantages of the system that has been made are cheap in the making, portable, and easy in operation.

\section{Conclusion}

A set of $\mathrm{Cu}$ contaminated water detection system using a red laser diode and photodiode sensor has been successfully manufactured. The photodiode sensor used in this system has characteristics: 1) transfer function of $\mathrm{V}=$ $0.0156 * \mathrm{I}+1.1897$ with very strong inputoutput relationship, 2) sensitivity of 0.0156 volts / lux, 3) repeatability of $98,31 \%$, and 4) saturation at light intensity input value $>200$ lux. Implementation of detection system at $\mathrm{Cu}$ contaminated water had a success of $97.50 \%$.

For future development it is advisable to do the followings: 1) This detection system can be developed by replacing with other light sensors such as phototransistor sensor, 2) The light intensity parameter can be replaced with other parameters such as conductivity, 3) Indicator to display the output not only on
LCD but via voice using buzzer and LED indicator, 4) Apply this detection system to other objects.

\section{References}

1. Supriyanto C.S., Kamal, Z. Analysis of Heavy Metals Contamination of $\mathrm{Pb}, \mathrm{Cu}$ and $\mathrm{Cd}$ on Freshwater Fish with Atomic Absorption Spectrometry (AAS) Method. Proceedings of The National Seminar of Nuclear Energy Technology III. 2012: 147-152. (in Indonesia)

2. Kristianingrum, S. Modification of Mercury Analysis Method in Aquatic Environment. Proceedings of The National Seminar on Research, Education and Application of Mathematics and Natural Sciences. 2007. (in Indonesia)

3. Rakhmadi, F.A., Dewi, A.R., Azizi, A.F. Design of Detection Device for $\mathrm{Cu}$ Contaminated Water Using Induction Principle. Indonesian Journal of Applied Physics. 2015 April;5(1):79-85.

4. Jung, K.H., Oh, E.T., Park, H.J., Lee, K.Y. Development of New Peptide-based Receptor of Fluorescent Probe with Femtomolar Affinity for $\mathrm{Cu}^{+}$and Detection of $\mathrm{Cu}^{+}$in Golgi Apparatus.

5. Kusnaedi, Processing Dirty Water For Drinking Water. Jakarta: Penebar Swadaya; 2010. (in Indonesia)

6. Sugiyono. Statistics for Research. Jakarta: Alfabeta; 2007. (in Indonesia)

7. Fraden, J. Handbook Of Modern Sensors: Physics, Designs, and Application, 4ndEd, New York: Springer-Verlag, 2010.

8. Suryono. Workshop on Quality Improvement of Lecturer and Student Research. Yogyakarta: Physics Department of UIN Sunan Kalijaga. 2012. (in Indonesia) 